\title{
Literature as Olympic Event?: Understanding the Scoreboard for Australian Women's Writing
}

\section{Katherine Bode}

Australian National University

\begin{abstract}
$\mathrm{T}$ he Olympics were in full swing when I was approached to be part of a town hall forum on gender equality in Australian literature at James Cook University. I have never watched much sport. But in July 2016 I had a three-month old baby to look after, meaning I was spending a lot of time on the couch watching daytime television; and when the Olympics are on, there's not much other daytime television on offer.
\end{abstract}

And for someone who doesn't watch a lot of sport-indeed, for a sleep-deprived parent-the Olympics are perfect. You don't have to know much about the individual events; you can switch on and off whenever you want; and perhaps most importantly, you know your teamin my case, Australia-and you can understand the scoreboard: how many medals do we have?

My Olympics watching activities might seem a long way away from the place of women in Australian literature. But sitting on the couch, watching the pole vaulting and feeding my baby, it occurred to me that there is a degree of overlap between my watching of the Olympics and an increasingly prominent means of understanding and advocating for women in literature: metrics regarding women's representation.

As is the case elsewhere, in Australia shortlists and awards for literary prizes invariably generate discussion about the number of women featured. In 2013, the Stella Prize was established in response to the low number of women awarded Australia's most prestigious literary prize, the Miles Franklin. (Stella was the first name of the author, Stella Maria Sarah Miles Franklin, who gave her name to this male-dominated award and who was read, at the time she was writing, as a man.)

Following in the footsteps of VIDA (http://www.vidaweb.org), an international measure of gender imbalances in book reviewing, in 2012 the Stella Count (http://thestellaprize.com.au) began tracking the proportions of books by men and women that received reviews in major Australian newspapers and magazines. Initially, women's books were significantly underrepresented, and in some publications the gender disparity was enormous (for instance, in $2012,80 \%$ of reviews in the Australian Financial Review were of books by male authors, as were $70 \%$ of reviews in the Weekend Australian). This difference has reduced over time, to 
the extent that, in 2016 book reviewing approached what the organizers of the Stella Count referred to as "gender parity," with $48 \%$ discussing books by women.

In years when women are well represented in prize shortlists and awards, and as the metrics for the Stella Count track toward parity, it is possible to feel as if gender equality in Australian literature is imminent. Certainly, the scoreboard seems obvious and easy to understand.

But as a literary historian-and one who has spent my career collecting and analysing literary data, including on the place of women in Australian literature-l'm not so sure. The rationale underlying these counts, and that of other measures such as the number of women on executive boards or in traditionally male dominated professions, is that of a defined imbalance that can be overcome by including women. However, the phenomenon of gender inequality in literary history suggests a more complex relationship between women's role and prominence in the literary field and the meanings and values ascribed to their activities. Instead of a forward trajectory where gender inequality can be banished, what occurs is a series of loops. Australian women's writing becomes more visible and acclaimed-so-called parity is achieved or even surpassed-only for those women authors to lose ground and fade from view.

Let me give you two examples from my research. The first relates precisely to the issue of book reviewing considered by the Stella Count. In the 1970s, Australian newspapers featured very little discussion of women's writing. Dorothy Hewett and Judith Wright garnered some attention, but the most reviewed authors were men, with David Ireland, Thomas Keneally, Patrick White and David Williamson prominent recipients of literary acclaim.

In the 1980s, this situation changed radically. All of a sudden Australian newspapers paid attention to women writers: Thea Astley, Barbara Hanrahan, Kate Grenville, Elizabeth Jolley and Christina Stead were among the most prominently discussed authors in this period. ${ }^{1}$ The 1980 s were proclaimed the decade of the woman writer, and it seemed as if gender equality in Australian literature had finally been achieved.

But it was just a decade. By the mid-1990s, Helen Demidenko/Darville was one of the only women writers to be widely discussed in Australian newspapers, and her prominence was largely the result of a notorious case of literary fraud rather than of literary acclaim. Reviewers had returned to discussing male authors, foregrounding a new group-including Peter Carey, Richard Flanagan, David Malouf, Alex Miller, Christos Tsiolkas and Tim Winton-around whom Australian literature was re-inscribed as mainly by and about men (Bode, 2012, pp. 143-166).

\footnotetext{
${ }^{1}$ Interestingly, in their analysis of gender proportions in reviewing in the Australian newspaper and the Australian Book Review in 1985, Melinda Hinkson and Julieanne Lamond show that books by male authors overwhelmingly dominated. The question of why particular women authors might receive a lot of attention across Australian periodicals, while women writers in general are underrepresented in these major publications, certainly warrants further investigation.
} 
The nineteenth century offers another example: this time not of reviewing but of publishing. Today, conceptions of nineteenth-century Australian literature are dominated by a canon of male authors such as Rolf Boldrewood, Marcus Clarke, Henry Kingsley, Henry Lawson and Banjo Paterson. But in the 1870 s and 1880s, Australian women writers such as Ada Cambridge, Rosa Praed and Catherine Helen Spence were much more likely than these celebrated men to experience the cultural and financial success that came with having a book published in Britain. By a major measure of esteem of the day, Australian women writers were more successful than their male counterparts (Bode, 2012, pp. 120-124).

The prominence of male authors in the nineteenth-century Australian literary canon has been attributed to local publishing practices, particularly the assertive way in which periodicals such as the Bulletin magazine promoted writing by men and a masculinist literary culture. My recent identification and analysis of fiction in the millions of pages of historical newspapers digitized by the National Library of Australia's Trove database (http://trove.nla.gov.au/) indicates that this practice was significantly more widespread. In the 1870 s and 1880 s, at the same time as women writers were enjoying success with book publication in Britain, multiple local fiction syndication agencies emerged. These published large amounts of Australian fictionoverwhelmingly by men-and sold it to the hundreds of provincial newspapers operating throughout the colonies (Bode, 2017, pp. 117-124).

Why were women writers, despite their success in Britain, largely excluded from local publishing practices? Rather than Australian periodicals simply or directly representing Australian literary culture as it occurred in the colonies, I think they were, at least in part, reacting defensively against women's success. In promoting the publication of male writers, these publications actively constructed a literary tradition where local male authors could prosper and be privileged. These periodicals created a space, in other words, that redefined literary success in terms of Australian men's writing.

Mark Twain (who was, himself, fairly widely published in nineteenth-century Australian newspapers) is reputed to have said that, "history doesn't repeat itself, but it does rhyme." Specific events never recur, in other words, but different events can have similarities or resonances despite their separation in time.

The historical rhyme I have described is of a repeated valuing then devaluing of Australian women's writing. Women achieve prominence in a particular arena, only to loose ground to male authors and to fade from public view. This occurs because the arena in which they succeed comes to be seen as no longer valuable and worthy of attention and acclaim, whether this arena be cultural and economic, for British book publication in the nineteenth century, or aesthetic and stylistic, with respect to the sensuous, often surrealist prose of literary fiction in the 1980s.

My aim in pointing out these historical patterns is not to suggest that measures such as the Stella Count should be abandoned. In identifying an area of literary culture where gender inequality manifests, the Stella Count serves a vital role in showing how forms of literary 
evaluation and consecration, which often pose as disinterested and objective, are in fact socially constructed, both shaped by and reproductive of gender norms. The increased reviews of women writers in Australian periodicals since the advent of the Stella Count suggests that, when the gendered assumptions underpinning social practices are exposed, they can interrogated and revised.

The most recent iteration of the Stella Count also demonstrates how cultural constructions of gender can persist even as they appear to reform. Organizers of the 2016 Count note that much of the increased attention to women writers that had occurred was in the form of short or medium length reviews. By contrast, most long reviews (of 1000 words or more) both discussed books by male authors and were written by male reviewers. The length of a review is a good indicator of how worthy of attention the reviewer and editor considers the book. Accordingly, this metric indicates that, even as more books by women are discussed, male authors are still considered the most important contributors to Australian literature as well as the most authoritative arbiters of value in the field (Harvey \& Lamond pp. 100-103).

But however valuable and nuanced the Stella Count, there are significant limits to its capacity to describe and influence gender inequality in Australian literature. As its organizers acknowledge, one thing their measures cannot show is "the ways in which the field [of book reviewing] as a whole is shrinking and changing shape" (Harvey \& Lamond, 2016, p.104). They are referring, in particular, to the declining importance of traditional print outlets in shaping literary culture.

This context points to what may be the larger cultural forces - the historical rhymes - at work in the contemporary field. Only the future will tell, but it seems strongly reminiscent of earlier valuations and devaluations of Australian women's writing that as women are increasingly, albeit unevenly, accorded attention in the form of reviews, the reviews themselves are less and less central to the way literary value is identified and ascribed. As occurred in the nineteenth century and the 1980s, as women make progress in a particular literary arena, the arena itself becomes less important in deciding literary meaning and value.

In the short term, keeping our eyes on the scoreboard that these metrics supply can help to redress what remains an orientation to male authors in Australian literary culture. But we cannot imagine that the scoreboard stays the same over time, or that once the runs are on the board, gender equality is achieved. The Olympics might actually have a great deal in common with Australian literature in terms of gender inequality, including the lack of recognition of women's achievements, unequal financial rewards, and continuing exclusion from particular events (Hill, 2016). But unlike the Olympics, in literary culture the type of scoreboards that have significance, and even the meaning of the score, can and often does change, repeatedly and routinely to male authors advantage.

Fortunately, literary culture has one important advantage over the Olympics: it's not predominantly a spectator sport. While the rules for what is valued can and do change, weas readers-also play a role in writing them. By making a conscious effort to buy books by 
women, to read and discuss them, and to celebrate their achievements and women's contributions to Australian literary culture, we can work to redefine scoreboard for Australian literature, and ensure that women writers are not once again pushed to the margins.

\section{References}

Bode, K. (2017). Fictional systems: Mass-digitization, network analysis, and nineteenthcentury Australian newspapers. Victorian Periodicals Review, 50 (1), 100-138.

Bode, K. (2012). Reading by numbers: Recalibrating the literary field. London: Anthem Press.

Harvey, M., \& Lamond, J. (2016). Taking the measure of gender disparity in Australian book reviewing as a field, 1985 to 2013. Australian Humanities Review, 60, 84-107.

Hill, L. (2016, August 10). Women athletes are still put in second place at the Olympics - it's time to sprint towards equality. The Conversation. Retrieved from https://theconversation.com/ 